\title{
Effect of Health Risk Appraisal Frequency on Change in Health Status
}

\author{
Chih-Wen Pai, PhD \\ Susan E. Hagen, MS \\ Joel Bender, MD, PhD \\ David Shoemaker \\ Dee W. Edington, PhD
}

\section{Learning Objectives}

- Discuss emerging data on the cost impact of health risk appraisals (HRAs), including the relative cost effects of improving health status in high-risk workers versus avoiding risk in risk-free workers.

- Interpret the new findings on the relationship between repeated HRAs and employee health risks.

- Summarize the role of HRAs in promoting desired employee health outcomes, including the contribution of wellness support and lifestyle management programs.

\section{Abstract}

Objective: To examine the association between repeat participation in health risk appraisal (HRA) and change in health status. If low-risk individuals get worse in their health status, the amount of cost increase tends to be greater than the amount of cost reduction when high-risk individuals improve their health status. Thus, "no change" in health status was considered a desired change along with "getting better" in this study. Methods: Longitudinal data (1997 to 2004) were used to measure change in health status and participation in HRAs and wellness programs. Results: Taking an HRA more than once between 2002 and 2004 was associated with a desired change in health status (staying no change or getting better $)(\mathrm{P}<0.0001)$. Additionally, participation in wellness programs during the same time period was also positively associated with a desired change $(\mathrm{P}<0.05)$. Conclusions: These results highlight the effect of continued engagement in health promotion activities on health status change. Combined with other education and intervention programs, HRAs can be useful tools in promoting and maintaining healthy lifestyles. (J Occup Environ Med. 2009;51: 429-434)

From the Health Management Research Center (Dr Pai, Dr Hagen, Dr Edington), University of Michigan, Ann Arbor, Mich; General Motor Corporation (Dr Bender), Pontiac, Mich; and International Union (Mr Shoemaker), United Automobile, Aerospace and Agricultural Implement Workers of America, Detroit, Mich.

Chih-Wen Pai and coauthors have no financial interest related to this research.

Address correspondence to: Chih-Wen Pai, PhD, Health Management Research Center, University of Michigan, 1015 E. Huron Street, Box 1689, Ann Arbor, MI 48104; E-mail: cwpai@umich.edu. Copyright (C) 2009 by American College of Occupational and Environmental Medicine

DOI: 10.1097/JOM.0b013e3181a039a4 continuing burden of health care cost has shifted the focus of health plans and employers from cost sharing to responsibility sharing. ${ }^{1,2}$ Findings from the Center for Studying Health System Change's 2007 site visits indicate that interest in prevention and wellness by health plans and employers has intensified. ${ }^{3}$ A 2007 survey of 573 US employers reports that $72 \%$ offered health risk appraisals (HRAs), ${ }^{4}$ whereas a 2002 survey of health plans reports that $64 \%$ of 50 million covered members were offered HRAs. ${ }^{5}$ HRAs are often used as a tool to improve health awareness and measure health risk. The Centers for Disease Control and Prevention recommends the use of HRAs with individualized feedback and education program in improving health behaviors in the workforce. ${ }^{6}$

Research has shown that adverse health risks are associated with higher health care cost. ${ }^{7,8}$ There is also emerging evidence that changes in health care costs and productivity follow changes in health risks over time in the same direction. ${ }^{9-11}$ Employers have long been interested in risk reduction hoping to contain health care cost. However, research has demonstrated that when low-risk individuals increase their health risks the increase in health cost is higher than the amount of reduced cost when high-risk individuals improve their health status. ${ }^{9}$ Thus, a more pragmatic approach may be to keep nondisease, nonrisk people disease and risk free, or to encourage people not to get worse if already experiencing health risks or health conditions. $^{12,13}$

Although much has been written on the ability of the HRA to measure 
risk $^{14-17}$ and the effect of HRA participation on lowering health care cost, ${ }^{18}$ little has been reported on the effect of multiple HRA participation on health status change, in the context of comprehensive health management. Therefore, this study examines if repeat participation in HRA process is associated with health status change. The change in health status of onetime HRA respondents was compared with that of respondents with multiple HRAs between 2002 and 2004. Involvement in HRAs and various wellness programs between 1997 and 2004 was also measured and controlled for in multivariate modeling.

\section{Materials and Methods}

A multistate manufacturing company instituted a worksite health promotion initiative in 1997. Program participation was on a voluntary basis and not associated with benefit package of employees. This health promotion initiative contained several programs targeting high-risk population as well as wellness support programs and mail-based HRAs for all employees. Health screening for biometric variables was offered on-site along with HRAs during the work hour. About $90 \%$ of HRAs had screening data. Individualized HRA feedback was provided after employees completed an HRA. The HRA served as a gateway to most other program components.

\section{Health Risk Appraisal}

The HRA questionnaire contains more than 60 questions and was originally developed by the Centers for Disease Control and Prevention and modified by the Carter Center and the University of Michigan Health Management Research Center. The HRA asks about lifestyle behaviors, presence of several medical conditions, and use of preventive services. This HRA system estimates 13 health factors, including alcohol use, blood pressure, body weight, cholesterol, cigarette smoking, health perception, high-density lipoprotein cholesterol, illness days, life satisfaction, major medical conditions, physical activity, safety belt use, and stress. Definition of high-risk status for each health factor was previously reported. ${ }^{19} \mathrm{On}$ the basis of overall health status, risk groups were defined as low (0 to 2 high risk), medium ( 3 to 4 high risk), and high (5 or more high risk). In this study, HRA data from 1999 to 2001 were used to measure health status at baseline and HRA data from 2002 to 2004 for follow-up measurement. There was no change in the wording of questions in HRAs measuring health risks or the definition of high risks during the study period. Because HRAs were the primary data source and HRA participation was generally low (around 20\% to $30 \%$ in a single year), a 3-year period was used for baseline and follow-up measurements, respectively, to increase the size of study population. Major changes in wellness support programs took place in 2005 with the on-site bioscreening program no longer offered in conjunction with the HRA program, resulting in relatively fewer employees taking HRAs. Therefore, this study only included data up to 2004.

\section{Population and Measures}

The study population consisted of individuals who were continuously hired from 1997 to 2004 at one plant in the Midwest and had at least one HRA for each of the baseline and follow-up periods. If employees had more than one HRA during the same period, the earliest HRA was selected for baseline and the latest one for follow-up. Overall health status was defined as the sum of health factors at high-risk status, so that a higher numeric value indicated a worse overall health status. Health status change as an outcome variable in this study was defined by comparing the sum of health factors at high risk status between baseline and follow-up. Employees were then categorized into three major groups: get better (follow-up sum less than baseline sum), no change (follow-up sum the same as baseline sum), and get worse (follow-up sum greater than baseline sum). Because there was some concern about a diminishing effect of previous program participation occurring in the more distant past, two variables were used to measure the frequency of HRA participation: previous participation and recent participation. The frequency of previous HRA participation (1997 to 2001) was measured as 3 to 5 HRAs versus 1 to 2 HRAs, whereas the frequency of recent HRA participation (2002 to 2004) was measured as one-time HRA participants (1 HRA) versus repeat HRA participants (2 to 3 HRAs).

\section{Analysis}

Bivariate comparison was conducted between one-time HRA participants and repeat HRA participants in recent years for demographic variables and previous HRA frequency. Similar comparisons were also made between these two HRA participant groups for the following variables: distribution of the three risk groups (low, medium, and high) at baseline and follow-up, the number of health factors at high risk at baseline and follow-up, and the overall health status change (get better, no change, and get worse). $t$ tests were used for statistical testing for continuous variables, and $\chi^{2}$ tests were used for categorical variables. Statistical significance was considered when $P$ value was less than 0.05 .

A multivariate logistic regression model was used to assess the association of HRA frequency on overall health status change. In this analysis, two groups (get better, no change) were combined to give the "not get worse" group, and the regression model was used to model the probability of not getting worse (vs getting worse). Key independent variable was recent HRA frequency (1 HRA vs 2 to 3 HRAs), along with demographic variables (age, sex, and employment status [hourly vs salaried]), baseline health status (presence of each of the 13 risk factors and a three-level risk group), previous 
HRA frequency (1997 to 2001), and gap in years between baseline (the first HRA between 1999 and 2001) and follow-up (the last HRA between 2002 and 2004). The inclusion of this gap variable was to control for the difference in length of time that individuals had for health status change to occur. To control for the effect of other health promotion activities, the model also included eligibility for lifestyle management programs and participation in various programs (lifestyle management programs, bioscreening, and wellness support programs) for each of the two periods (1997 to 2001 and 2002 to 2004). Inclusion of these variables measuring eligibility for and participation in more targeted, high-intensity lifestyle management program served to control for the difference in health status and self motivation between the two comparison groups.

\section{Results}

\section{Demographics}

A total of 3384 continuously hired individuals were included for analysis. The average age was 50 years and $83 \%$ of the study population were male (Table 1). About $50.4 \%$ of the total study population took HRAs more than once in recent years $(2002$ to 2004). Demographics were similar between employees with one HRA and those with 2 to 3 HRAs in recent years. Repeat HRA participants in recent years also had more HRAs (3 to 5 HRAs) in the past (1997 to

TABLE 1

Demographics by HRA Frequency 2002 to 2004

\begin{tabular}{|c|c|c|c|c|}
\hline \multirow[b]{2}{*}{ Characteristic } & \multirow[b]{2}{*}{$\begin{array}{c}\text { All } \\
(N=3384)\end{array}$} & \multirow[b]{2}{*}{$\begin{array}{c}1 \text { HRA } \\
(N=1676)\end{array}$} & \multicolumn{2}{|c|}{$\begin{array}{l}\text { HRA Frequency } \\
\text { 2002-2004 }\end{array}$} \\
\hline & & & $\begin{array}{c}\text { 2-3 HRA } \\
(N=1708)\end{array}$ & $\boldsymbol{P}^{\star}$ \\
\hline \multicolumn{5}{|l|}{ Demographics } \\
\hline Male (\%) & $83.1 \%$ & $83.5 \%$ & $82.7 \%$ & 0.5336 \\
\hline Age (year, at baseline) & 50.0 & 49.8 & 50.1 & 0.1793 \\
\hline Hourly employees (\%) & $83.7 \%$ & $81.7 \%$ & $85.6 \%$ & 0.0024 \\
\hline HRA frequency $1997-2001$ & & & & $<0.0001$ \\
\hline 1-2 HRAs & $39.8 \%$ & $48.4 \%$ & $31.4 \%$ & \\
\hline 3-5 HRAs & $60.2 \%$ & $51.6 \%$ & $68.6 \%$ & \\
\hline
\end{tabular}

${ }^{*}$ Comparison made between one-time and repeat HRA groups ( $t$ test for the variable of age and $\chi^{2}$ test for the other variables).

HRA indicates health risk appraisal.

2001), compared with one-time HRA participants (68.6\% vs $51.6 \%)$.

\section{Risk and Health Status}

There were no major differences in the distribution of risk groups or the number of health factors at high risk at baseline between one-time and repeat HRA participants (Table 2). Overall health status improved for both HRA groups, with each group experiencing a decreased number of health factors at high-risk status and an increased proportion of employees in the low-risk group. However, those employees with repeat HRAs displayed a greater degree of favorable change than did one-time HRA employees. For example, repeat HRA employees had an $8.5 \%$ point increase in the population of the low-risk group, compared with a $3.2 \%$ point increase for the one-time HRA employees. As to health status change, $41.4 \%$ of employees in the HRA repeat group improved their health status (number of health factors at high risk status decreased) and $26 \%$ had worse health status, compared with $38.1 \%$ and $31 \%$, respectively, among the one-time HRA employees. In other words, a higher proportion of employees in the HRA repeat group did not get worse in overall health status, compared with those in the one-time HRA group.

\section{TABLE 2}

Health Status and Health Status Change by HRA Frequency 2002 to $2004(N=3384)$

1 HRA $(N=1676)$

2-3 HRAs $(N=1708)$

\begin{tabular}{|c|c|c|c|c|c|c|}
\hline & & \\
\hline & Baseline & Follow-Up & Change* $^{*}$ & Baseline & Follow-Up & Change* $^{*}$ \\
\hline Risk group ( $P$ value $) \dagger$ & & & & $(0.528)$ & $(0.0002)$ & \\
\hline Low (0-2 risks) & $56.0 \%$ & $59.2 \%$ & 3.2 & $57.4 \%$ & $65.9 \%$ & 8.5 \\
\hline Medium (3-4 risks) & $30.0 \%$ & $28.8 \%$ & -1.2 & $29.9 \%$ & $24.9 \%$ & -5.0 \\
\hline High (5 or more risks) & $14.0 \%$ & $12.0 \%$ & -2.0 & $12.7 \%$ & $9.2 \%$ & -3.5 \\
\hline $\begin{array}{l}\text { Number of health factors at high risk } \\
(P \text { value }) \dagger\end{array}$ & 2.5 & 2.4 & -0.1 & $2.4(0.1019)$ & $2.1(<0.0001)$ & -0.3 \\
\hline Overall health status change ( $P$ value $) \dagger$ & & & & & & $(0.0062)$ \\
\hline Get better & & & $38.1 \%$ & & & $41.4 \%$ \\
\hline No change & & & $30.9 \%$ & & & $32.6 \%$ \\
\hline Get worse & & & $31.0 \%$ & & & $26.0 \%$ \\
\hline
\end{tabular}

*Percentage point change for risk group (follow-up minus baseline).

†Comparison between one-time and repeat HRA groups during the same period. 
TABLE 3

Select Results From Logistic Regression $(N=3384)^{\star}$

\begin{tabular}{|c|c|c|}
\hline Variable & Odds Ratio† & $P \ddagger$ \\
\hline \multicolumn{3}{|l|}{ Demographics (as of 2002) } \\
\hline Male & 0.930 & 0.5573 \\
\hline Employment status (hourly vs salaried) & 0.793 & 0.0889 \\
\hline Age (at baseline) & & 0.0107 \\
\hline \multicolumn{3}{|l|}{ HRA frequency } \\
\hline 1997-2001 (3-5 vs 1-2 HRAs) & 1.173 & 0.1333 \\
\hline $2002-2004$ (2-3 vs 1 HRAs) & 1.861 & $<0.0001$ \\
\hline \multicolumn{3}{|l|}{ Lifestyle management program } \\
\hline Any program 1997-2001 (any vs 0 yr) & 0.978 & 0.8397 \\
\hline Any program 2002-2004 (any vs 0 yr) & 1.027 & 0.8453 \\
\hline \multicolumn{3}{|l|}{ Wellness program } \\
\hline Any program 1997-2001 (any vs 0 yr) & 0.806 & 0.0626 \\
\hline Any program 2002-2004 (any vs 0 yr) & 1.239 & 0.0310 \\
\hline \multicolumn{3}{|l|}{ Individual health risk at baseline } \\
\hline Alcohol use (>14 drinks per week) & 2.164 & 0.0019 \\
\hline Body mass index $\left(\geq 27.5 \mathrm{~kg} / \mathrm{m}^{2}\right)$ & 2.021 & $<0.0001$ \\
\hline Current cigarette smoker & 1.602 & 0.0007 \\
\hline $\mathrm{HDL}(1-34$ mg/dL) & 3.247 & $<0.0001$ \\
\hline Health perception (fair or poor) & 1.526 & 0.0353 \\
\hline High blood pressure & 3.442 & $<0.0001$ \\
\hline High cholesterol (>239 mg/dL) & 4.626 & $<0.0001$ \\
\hline Illness days ( $>5 \mathrm{~d}$ a yr) & 2.489 & $<0.0001$ \\
\hline Life satisfaction (partly or not satisfied) & 1.994 & $<0.0001$ \\
\hline Major medical conditions & 1.767 & 0.0003 \\
\hline Physical activity ( $<1$ time per wk) & 3.196 & $<0.0001$ \\
\hline Safety belt use $(<90 \%$ of the time) & 2.301 & $<0.0001$ \\
\hline Stress & 3.181 & $<0.0001$ \\
\hline
\end{tabular}

*Health status change (not get worse vs get worse) as dependent variable; $R^{2}=0.242$; three-level risk group at baseline was significant $(P<0.001)$.

†Odds ratio not reported for continuous variables.

$\ddagger$ Overall type $3 P$ value.

\section{Logistic Regression}

Select results from regression modeling are reported in Table 3 . Compared with one-time HRA participants from 2002 to 2004, employees with two to three HRAs during the same time period had an odds of 1.861 for not getting worse (staying no change or getting better) in terms of their health status $(P<0.0001)$. Similarly, more HRA participation in the past (1997 to 2001) had a positive, though not statistically significant, effect on health status change. A significant, positive association was also observed with wellness support program participation but only if that participation occurred in recent years $(P<0.05)$. The presence of each of the 13 risk factors at baseline was significantly associated with health status change. As expected, eligibility for targeted, more intense lifestyle management programs (as a proxy measure of health status) was negatively associated with desired change in health status $(P<0.0001$, not reported in Table 3), but participation in these targeted programs had no statistically significant impact on health status change.

\section{Discussion}

This study assessed the association between frequency of HRA participation and health status change. The results indicated that both repeat HRA participation and wellness program participation between 2002 and 2004 were associated with a desired change in health status (defined as staying the same or getting better). A positive association was also observed for more HRA participation in the past (1997 to 2001), although this relationship was not statistically significant.

These findings support the value of repeat HRA participation in maintaining or improving individual's health status. Studies have reported that an instrument of measurement like the HRA influences motivation for behavior change. ${ }^{20,21}$ Research argues that an HRA can be a useful tool in successful health promotion programs, but it must be part of a comprehensive program of assessment, education, and intervention. ${ }^{18}$ In addition, previous research contends that continued wellness programs may produce more lasting benefits. $^{22}$ Therefore, multielement wellness programs over time, including educational and targeted interventions in conjunction with HRAs, are needed to promote health. ${ }^{23,24}$

No argument exists against the relationship between higher risk and higher health care cost, but optimal strategies for facilitating and sustaining changes are still elusive. Efforts to maintain desired behaviors and change health risks often include education and targeted interventions. Repeat participation in wellness programming is crucial to produce sustainable outcomes but may be challenging. ${ }^{25,26}$ Financial incentives (or disincentives) have been used to promote wellness participation and some success for this strategy has been reported. ${ }^{12,27-30}$

As employers increasingly view workforce health as a business asset and invest in strategies to improve or maintain the health and productivity of employees, HRAs serve as both measurement and education tools when incorporated in comprehensive worksite wellness programs. Similarly, more health plans are actively engaged in improving health and preventing adverse health events among their covered members and are offering HRAs to their members to achieve these goals. Health plans may use HRAs to identify members with potential future high cost for early intervention. The partnership among all stakeholders creates a 
win-win situation, because healthier individuals are more productive and cost less. ${ }^{8,31,32}$

\section{Limitations}

The study population included employees with at least one HRA during each of the two measurement periods (baseline [1999 to 2001] and follow-up [2002 to 2004]). It is reasonable to expect that repeat HRA participants were already interested in and committed to their health to the extent that they took HRAs more than once. Thus, the study results may not be readily generalized to the entire workforce. Consequently, one could argue that desired change in health status results from self motivation, rather than more frequent HRA participation. This study conducted multivariate modeling to control for HRA participation in the past and participation in voluntary wellness programs over time. In this way, the bias of self-selection was addressed, if not completely eliminated. One recent study found intention for change as stated in HRAs was significantly associated with increasing physical activity level and quitting smoking. ${ }^{33}$ Future research may study multiple factors facilitating behavior change, such as intention or motivation and program participation.

Measurement for intensity of wellness program participation has always been a challenge, because various wellness programs differ in goal, frequency, and duration. This study considered all programs equally and measured any participation in a given time period (1997 to 2001 or 2002 to 2004). Because this approach might be oversimplified, a separate measure first identified any wellness program participation in a given year and then counted the number of program years. Similar results were observed using this revised set of variables for wellness participation. To better capture the effect of wellness program participation, an enhanced measure of program intensity would require a detailed description of wellness pro- gram and an algorithm to assign quantifiable values to each program. In addition, a better tracking system is needed to record participation level among participants over time.

Similarly, a simple measure of participation in targeted lifestyle management program may overlook the effect of participation intensity such as the number of coaching sessions. Along with the fact that program participation was voluntary, one could not truly assess the effect of lifestyle management program without considering program quality. Because only employees meeting certain criteria were eligible to participate in high-intensity lifestyle management program, a match between program participants and nonparticipants among eligible employees is needed to study the program effect on health status change.

Another limitation is the data source. Most of the data came from self-reported HRAs. It is possible that individuals did not answer the HRA questionnaire candidly. For example, preliminary analysis has revealed that individuals tended to underreport their age and body weight. In this study, however, the screening results for biometric variables were incorporated as part of HRA data, and about $90 \%$ of HRAs each year had screening data. Age was calculated based on date of birth from the personnel file. Thus, concerns over questionable measurements of health risks and the demographics should be diminished to an appreciable extent given the controls in place.

\section{Conclusion}

This study used 8-year HRA and wellness data to document program participation and measure its association with health status change among employees from a manufacturing company. A multicomponent, worksite health promotion initiative launched in 1997 reflects the longterm commitment of the employer to workforce health. The present study suggests that repeat engagement in wellness activities such as HRAs over years is critical to health status maintenance and improvement. Future study may examine financial and nonfinancial incentives deigned to encourage initial and continuing participation in health promotion activities.

\section{References}

1. Gold B. The increasing role of employers in employee health. Manag Care Interface. 2007;20:48.

2. Cross M. More plans discover value of health risk assessments. Manag Care. 2004;13:54-56, 59-60.

3. Draper DA, Ginsburg PB. Health care cost and access challenges persist: initial findings from HSC's 2007 site visits. Issue Brief Cent Stud Health Syst Change. 2007:1-6.

4. 12th Annual National Business Group on Health/Watson Wyatt Survey Report. Watson Wyatt Worldwide; 2007. 2007US-0031.

5. 2002 AHIP Survey of Health Insurance Plans. Washington, DC: America's Health Insurance Plans; 2002.

6. Okie S. The employer as health coach. N Engl J Med. 2007;357:1465-1469.

7. Pronk NP, Goodman MJ, O'Connor PJ, Martinson BC. Relationship between modifiable health risks and short-term health care charges. JAMA. 1999;282: 2235-2239.

8. Yen L, Schultz A, Schnueringer E, Edington DW. Financial costs due to excess health risks among active employees of a utility company. J Occup Environ Med. 2006;48:896-905.

9. Edington DW, Yen LT, Witting P. The financial impact of changes in personal health practices. J Occup Environ Med. 1997;39:1037-1046.

10. Burton WN, Chen CY, Conti DJ, Schultz $\mathrm{AB}$, Edington DW. The association between health risk change and presenteeism change. J Occup Environ Med. 2006; 48:252-263.

11. Edington DW. Emerging research: a view from one research center. Am J Health Promot. 2001;15:341-349.

12. Poole K, Kumpfer K, Pett M. The impact of an incentive-based worksite health promotion program on modifiable health risk factors. Am J Health Promot. 2001; 16:21-26.

13. Cross M. Spend money on healthy people! Manag Care. 2004;13:20-26.

14. Edington D, Yen L, Braunstein A. The reliability and validity of HRAs. In: Hyner G, Peterson K, Travis J, Dewey J, Foerster J, Framer E, eds. SPM Hand- 
book of Health Assessment Tools. 3rd ed. Pittsburgh: The Society of Prospective Medicine and Institute for Health and Productivity Management; 1999:135-141.

15. Giles WH, Croft JB, Keenan NL, Lane MJ, Wheeler FC. The validity of selfreported hypertension and correlates of hypertension awareness among blacks and whites within the stroke belt. Am J Prev Med. 1995;11:163-169.

16. Gillum RF, Sempos CT. Ethnic variation in validity of classification of overweight and obesity using self-reported weight and height in American women and men: the Third National Health and Nutrition Examination Survey. Nutr J. 2005;4:27-34.

17. Kuczmarski MF, Kuczmarski RJ, Najjar M. Effects of age on validity of selfreported height, weight, and body mass index: findings from the Third National Health and Nutrition Examination Survey, 1988-1994. J Am Diet Assoc. 2001; 101:28-34.

18. Serxner SA, Gold DB, Grossmeier JJ, Anderson DR. The relationship between health promotion program participation and medical costs: a dose response. J Occup Environ Med. 2003;45:1196-1200.

19. Musich S, McDonald T, Hirschland D, Edington DW. Examination of risk status transitions among active employees in a comprehensive worksite health promotion program. J Occup Environ Med. 2003;45:393-399.

20. Hughes JR, Keely JP, Fagerstrom KO,
Callas PW. Intentions to quit smoking change over short periods of time. Addict Behav. 2005;30:653-662.

21. Naylor PJ, Simmonds G, Riddoch C, Velleman G, Turton P. Comparison of stage-matched and unmatched interventions to promote exercise behaviour in the primary care setting. Health Educ Res. 1999;14:653-666.

22. Glasgow RE, McCaul KD, Fisher KJ. Participation in worksite health promotion: a critique of the literature and recommendations for future practice. Health Educ Q. 1993;20:391-408.

23. Muto T, Yamauchi K. Evaluation of a multicomponent workplace health promotion program conducted in Japan for improving employees' cardiovascular disease risk factors. Prev Med. 2001;33: 571-577.

24. Whitmer RW, Pelletier KR, Anderson DR, Baase CM, Frost GJ. A wake-up call for corporate America. J Occup Environ Med. 2003;45:916-925.

25. Jeffery RW, Forster JL, French SA, et al. The Healthy Worker Project: a work-site intervention for weight control and smoking cessation. Am J Public Health. 1993; 83:395-401.

26. Lynch WD, Chen C-Y, Bender J, Edington DW. Documenting participation in an employer-sponsored disease management program: selection, exclusion, attrition, and active engagement as possible metrics. J Occup Environ Med. 2006;48:447-454.
27. Herman CW, Musich S, Lu C, Sill S, Young JM, Edington DW. Effectiveness of an incentive-based online physical activity intervention on employee health status. J Occup Environ Med. 2006;48: 889-895.

28. Follick MJ, Fowler JL, Brown RA. Attrition in worksite weight-loss interventions: the effects of an incentive procedure. J Consult Clin Psychol. 1984;52:139-140.

29. Tu HT, Ginsburg PB. Benefit design innovations: implications for consumerdirected health care. Issue Brief Cent Stud Health Syst Change. 2007;109:1-6.

30. Pescatello LS, Murphy D, Vollono J, Lynch E, Bernene J, Costanzo D. The cardiovascular health impact of an incentive worksite health promotion program. Am J Health Promot. 2001;16:16-20.

31. Wright D, Adams L, Beard MJ, et al. Comparing excess costs across multiple corporate populations. J Occup Environ Med. 2004;46:937-945.

32. Musich S, Hook D, Baaner S, Edington DW. The association of two productivity measures with health risks and medical conditions in an Australian employee population. Am J Health Promot. 2006; 20:353-363.

33. Pai CW, Edington DW. Association between behavioral intention and actual change for physical activity, smoking, and body weight among an employed population. J Occup Environ Med. 2008; 50:1077-1083. 